http://jurnal.bhmm.ac.id/index.php/jpkm

Corresponding Author.

email address : perwiraningtyas@gmail.com

Received : 2 Juli 2021 Revised : 19 Agustus 2021 Accepted : 2 Oktober 2021

\title{
Video Animasi sebagai Media Edukasi Pengetahuan SADARI pada Wanita Usia Subur
}

\author{
Meriana Dangga Mesa, ${ }^{\square}$ Pertiwi Perwiraningtyas, Susmini \\ Program Studi Keperawatan Fakultas Ilmu Kesehatan \\ Universitas Tribhuwana Tunggadewi, Indonesia
}

\begin{abstract}
ABSTRAK
Pemeriksaan payudara sendiri (SADARI) adalah cara yang efektif untuk mendeteksi kemungkinan terjadinya kanker payudara. Namun, masih banyak wanita yang belum memahami mengenai pemeriksaan tersebut. Tujuan penelitian ini untuk mengetahui Pengaruh Video Animasi Terhadap Pengetahuan SADARI Pada Wanita Usia Subur di Kelurahan Tlogomas Kota Malang. Desain penelitian Quasi Eksperimental yaitu One-Group Pre-Post Test Design. Populasi dalam penelitian sebanyak 54 wanita usia subur dengan teknik pengambilan sampling simple random sampling, sampel sebanyak 48 orang dengan kriteria inklusi berusia 15-25 tahun dan bersedia menjadi responden dengan mengisi informed consent. Teknik pengumpulan data menggunakan kuesioner. Metode analisa data yaitu marginal homogeneity. Hasil penelitian didapatkan bahwa sebelum diberikan edukasi dengan media video animasi terhadap pengetahuan SADARI pada wanita usia subur terdapat 24 orang (50\%) responden memiliki pengetahuan cukup dan sebagiannya memiliki pengetahuan kurang. Setelah diberikan edukasi terdapat peningkatan dengan kategori baik sebanyak 34 orang $(70,8 \%)$. Berdasarkan hasil uji analisis didapatkan nilai p-value sebesar 0,000<0,05. Disimpulkan bahwa ada perbedaan yang signifikan pengetahuan SADARI sebelum dan sesudah dilakukan edukasi dengan media video animasi pada wanita usia subur di Kelurahan Tlogomas Kota Malang. Hasil penelitian ini diharapkan dapat digunakan sebagain pedoman asuhan keperawatan khususnya sebagai media promosi kesehatan di lingkup tatanan masyarakat untuk menekan prevalensi terjadinya kanker payudara.
\end{abstract}

Kata kunci: Kanker payudara, SADARI, Video animasi

Video Animation as Education Examination Media Knowledge Breast Self Examination in Women Fertile

\begin{abstract}
Breast self-examination (BSE) is an effective way to detect the possibility of breast cancer. However, there are still many women who did not understand about the examination. The purpose of this study was to determine the effect of animated videos on BSE knowledge in women fertileage in Tlogomas Village, Malang City. Quasi experimental research is One-Group Pre-Post Test Designed. The population in this study were 54 women fertileage with a simple random sampling technique, a sample of 48 people with inclusion criteria aged 15-25 years and willing to become respondents by filled out informed consent. Data collection techniques used a questionnaire. The data analysis method was marginal homogenity. The results showed that before being given education with animated video media on BSE knowledge in women fertileage, there were $24(50 \%)$ respondents who had sufficient knowledge and some of them had less knowledge. After being given education there was an increase in the good category as many as 34 people (70.8\%). Based on the analysis test results obtained p-value of $0.000<0.05$. It was concluded that there was a significant difference in BSE knowledge before and after education with animated video media for women fertileage in Tlogomas Village, Malang City. The results of this study were expected to be used as a guide for nursing care, especially as a medium for health promotion in the scope of the community to reduce the prevalence of breast cancer.
\end{abstract}

Kata kunci: Breast Cancer,Breast Self-Examination, Video Animation.

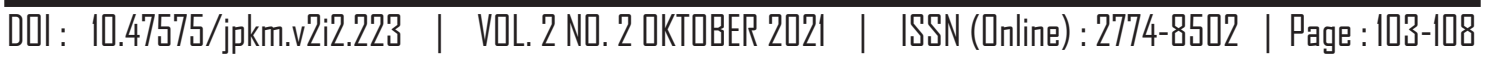




\section{PENDAHULUAN}

Kanker payudara ( $\mathrm{Ca}$ Mammae) merupakan pertumbuhan sel payudara yang tidak terkontrol karena terjadi perubahan abnormal dari gen yang berperan dalam pembelahan sel. Penyebab kanker payudara akibat sel yang ada dalam tubuh mengalami kemunduran, yakni perubahan dari sel sehat yang tidak berfungsi normal menjadi sel tumor (Patandianan, Suarayasa \& Towidjojo, 2015). Kejadian kanker payudara meningkat sesuai dengan bertambahnya usia, akan tetapi usia muda juga bukan jaminan aman dari kanker payudara. Tanda yang mungkin muncul pada stadium dini seperti ada benjolan kecil di payudara namun tidak terasa nyeri (Suraya, Romus \& Suyanto, 2015).

Data Globocan (2018), mengemukakan angka penderita kanker payudara di seluruh dunia sebanyak 18,1 juta yang menyebabkan sebesar 9,6 juta kematian. Angka kejadian kanker payudara menduduki peringkat ke dua dari kanker serviks yang menduduki peringkat pertama untuk perempuan di Indonesia tahun 2018 yaitu sebesar 42,1 per 100.000 penduduk dengan rata-rata kematian 17 per 100.000 penduduk (Kemenkes RI, 2019). Penderita kanker payudara di Provinsi Jawa Timur sekitar 17 ribu orang dan mayoritas berada di umur produktif yaitu 17-35 tahun (Dinkes Jatim, 2019). Persentase penderita kanker payudara di Kota Malang tahun 2019 sebanyak 2,26\% (Dinas Kesehatan Malang, 2019).

Upaya yang dilakukan wanita untuk mendeteksi kejadian kanker payudara yaitu dengan melakukan pemeriksaan payudara sendiri (SADARI). SADARI merupakan deteksi dini kanker payudara yang sangat dianjurkan bagi seluruh wanita yang memasuki usia dewasa minimal 1 bulan sekali. Tindakan SADARI sangat penting karena hampir $85 \%$ benjolan di payudara wanita ditemukan oleh penderita sendiri (Abdullah, Tangka, \& Rottie, 2013).

Menurut WHO (2019), tindakan SADARI pada wanita untuk mendeteksi kanker payudara masih rendah, didapatkan di dunia tahun 2019 tercatat $53,7 \%$ wanita usia subur tidak pernah melakukan SADARI dan sisanya 46,3\% pernah melakukan SADARI. Menurut Kemenkes RI (2019) pravelensi perilaku SADARI pada wanita usia subur di Indonesia sangat rendah sebanyak 95,6\% tidak pernah melakukan SADARI dan hanya $4,4 \%$ saja wanita usia subur yang pernah melakukan SADARI, di Provinsi Jatim sebanyak 94,3\% wanita tidak pernah melakukan SADARI dan hanya 5,7\% saja wanita yang pernah melakukan SADARI, sedangkan di Kota Malang sebanyak 92,0\% wanita tidak pernah melakukan SADARI dan hanya $8 \%$ saja wanita yang pernah melakukan SADARI. Masalah tersebut terjadi karena sebanyak 42,2\% wanita memiliki pengetahuan kurang tentang SADARI (Kemenkes RI, 2019). Pentingnya pengetahuan wanita tentang SADARI untuk meningkatkan minat melakukan pemeriksaan payudara sendiri yang bertujuan untuk deteksi awal kenker payudara sehingga bisa melakukan tindakan lebih cepat dalam penanganannya (Suastina dkk., 2013). Pengetahuan dapat mempengaruhi seseorang secara alamiah dan mendasari pribadi tersebut dalam mengambil keputusan yang rasional dan menerima perilaku yang baru kemudian akan menghasilkan persepsi dan tindakan. Pengetahuan sebagai informasi yang diketahui wanita tentang SADARI yang berperan penting dalam meningkatkan sikap dan perilaku melakukan pemeriksaan payudara sendiri (Patandianan, Suarayasa \& Towidjojo, 2015). Penelitian Abdullah, Tangka, \& Rottie (2013), membuktikan bahwa pengetahuan yang kurang menyebabkan wanita tidak bisa melakukan SADARI sehingga tidak mengetahui status kesehatan payudaranya.

Salah satu cara yang efektif untuk meningkatkan pengetahuan wanita tentang SADARI yaitu memberikan penyuluhan kesehatan menggunakan media video animasi. Penyuluhan kesehatan tentang SADARI menggunakan media video bertujuan untuk meningkatkan pengetahuan wanita dalam melakukan SADARI mandiri di rumah. Kelebihan media video animasi sebagai edukasi yaitu memberikan informasi secara lengkap melalui video tindakan SADARI sehingga seseorang bisa dengan mudah memperagakannya sendiri (Ibrahim, 2015). Penelitian Suastina dkk. (2013), menjelaskan bahwa penyuluhan kesehatan sangat berperan penting untuk meningkatkan pengetahuan dan perilaku wanita untuk melakukan SADARI. 
Berdasarkan hasil studi pendahuluan pada tanggal 18 Desember 2020 dengan melakukan mewawancarai 10 Wanita Usia Subur di RW 06 RT 07 Kelurahan Tlogomas Kota Malang didapatkan sebanyak 8 orang tidak pernah melakukan SADARI karena tidak mengetahui cara melakukan SADARI dan sebanyak 2 orang pernah melakukan SADARI karena pernah mendapatkan penyuluhan kesehatan tentang SADARI dari tenaga kesehatan. Hal ini membuktikan bahwa pengetahuan mendukung sikap dan perilaku wanita untuk melakukan SADARI. Berdasarkan latar belakang tersebut peneliti tertarik untuk melakukan penelitian dengan judul "Video Animasi sebagai Media Edukasi Pengetahuan SADARI pada Wanita Usia Subur".

\section{METODE PENELITIAN}

Desain Penelitian menggunakan OneGroup Pra-Post Test Design. Populasi yang digunakan adalah wanita usia subur di RW 06 RT 07 Kelurahan Tlogomas Kota Malang sebanyak 54 orang berdasarkan data Januari 2021. Jumlah sampel didapatkan sebanyak 48 orang yang telah dipilih dengan metode simple random sampling dengan kriteria berusia 15-25 tahun dan mengisi lembar Informed Consernt. Variabel independen dalam penelitian ini adalah edukasi menggunakan media video animasi. Sedangkan untuk variabel dependen adalah pengetahuan SADARI. Instrumen yang digunakan yaitu lembar kuesioner Bustan (2007), sebanyak 24 pertanyaan berdasarkan indikator pengertian SADARI, tujuan SADARI, cara melaksanakan SADARI, waktu pemeriksaan SADARI dan masalah yang ditemukan saat SADARI.

Penelitian dilaksanakan di RW 06 RT 07 Kelurahan Tlogomas Kota Malang, dimana waktu penelitian dilaksanakan pada bulan Maret 2021. Prosedur penelitian setelah responden bersedia untuk terlibat dalam penelitian, responden diberikan lembar pre test kuesioner pengetahuan SADARI. Setelahnya diberikan edukasi kesehatan dengan video animasi SADARI dengan durasi 15 menit (tautan video https://youtu.be/VjFJ8R2xwoE). Setelah itu, responden mengisi lembar post test.

Pengumpulan data dilakukan dengan memenuhi kaidah etika penelitian yaitu: informed consent, Anonymity, Confidentiality, bebas dari eksploitasi, veracity, dan right to justice in fair treatment. Setelah data terkumpul, kemudian data dikategorikan menjadi baik (skor 76\%-100\%), cukup (56\%-75\% dan kurang $(<55 \%)$. Setelahnya data diolah dan dianalisis dengan uji marginal homogenity dengan nilai alpha sebesar $5 \%$.

\section{HASIL DAN PEMBAHASAN}

Berdasarkan Tabel 1 didapatkan hampir seluruhnya usia responden $20-25$ tahun $(85,4 \%)$ dan keseluruhan responden belum menikah.

Berdasarkan Tabel 2, didapatkan untuk masing-masing kategori pengetahuan SADARI yaitu cukup dan kurang memiliki prosentasi yang sama yaitu 50\%. Untuk kategori kurang, setelah diberikan perlakuan didapatkan $25 \%$ diantaranya menjadi cukup, dan $25 \%$ diantaranya menjadi baik. Sedangkan untuk kategori kurang cukup, setelah diberikan perlakuan didapatkan hampeir separuh responden meningkat menjadi kategori baik $(45.8 \%)$.

Dari hasil uji Marginal Homogeneity didapatkan bahwa ada pengaruh pemberian edukasi dengan video animasi terhadap pengetahuan SADARI dengan nilai $\mathrm{p}$ sebesar 0,000 .

\section{Pengetahuan SADARI Sebelum Diberikan Edukasi dengan Media Video Animasi}

BerdasarkanTabel2, menunjukkanpengetahuan wanita usia subur tentang pemeriksaan payudara

Tabel 1

Karakteristik Responden

\begin{tabular}{cccc}
\hline Variabel & Kategorik & F & $\%$ \\
\hline Usia & $15-19$ tahun & 7 & 14,6 \\
& $20-25$ tahun & 41 & 85,4 \\
Status Pernikahan & Belum menikah & 48 & 100,0 \\
\hline
\end{tabular}

Sumber: Data Primer Diolah, 2021 
sendiri sebelum diberikan video animasi tentang pengetahuan SADARI untuk kategori kurang dan cukup masing-masing memiliki prosentasi $50 \%$. Pengetahuan tersebut meliputi pengertian pemeriksaan payudara sendiri, tujuan, waktu pelaksanaan, cara melakukan dan masalah yang ditemukan saat melakukan pemeriksaan payudara sendiri. Pengetahuan adalah hasil tau yang diperoleh seseorang dengan menggunakan pengindaraannya dalam mengamati atau melihat suatu objek tertentu (Notoadmojo, 2017). Faktor yang mempengaruhi pengetahuan cukup yaitu umur, status pernikahan. Faktor yang mempengaruhi di antaranya pendidikan, pengalaman, usia, dan informasi (Hendra, 2017).

Faktor umur didapatkan cukup dari setengah responden berumur 20-25 tahun, artinya semakin bertambah umur seseorang maka pengalaman juga semakin bertambah sehingga cukup mengetahui cara penanganan pemeriksaan payudara sendiri. Menurut Notoadmodjo (2014), umur adalah umur responden dalam tahun terakhir ressponden. Umur sangat erat hubungannya dengan pengetahuan seseorang, karena semakin bertambah usia maka semakin banyak pula pegetahuannya.

Pengetahuan yang cukup perlu ditingkatkan menjadi baik sehingga seluruh wanita usia subur mampu melakukan SADARI secara mandiri dengan baik dan benar. Salah satu upaya untuk meningkatkan pengetahuan wanita tentang SADARI yaitu memberikan penyuluhan kesehatan dengan menggunakan media video animasi. Menurut (Ibrahim, 2015) mengatakan bahwa Kelebihan media video animasi sebagai edukasi yaitu memberikan informasi secara lengkap melalui video tindakan SADARI sehingga seseorang bisa dengan mudah memperagakannya sendiri.
Pengetahuan SADARI Setelah Diberikan Penyuluhan Kesehatan Dengan Media Video Animasi Pada Wanita Usia Subur Di RW 06 RT 07 Kelurahan Tlogomas Kota Malang.

Berdasarkan Tabel 2, menunjukkan pengetahuan dalam melakukan pemeriksaan payudara sendiri setelah diberikan video animasi tentang SADARI pada 48 responden terdapat peningkatan pengetahuan tentang SADARI hampir seluruhnya 34 orang $(70,8 \%)$ responden memiliki pengetahuan baik tentang pengetahuan pemeriksaan payudara sendiri di RW 06 RT 07 Kelurahan Tlogomas Kecamatan Lowokwaru Kota Malang.

Faktor yang meningkatkan pengetahuan SADARI pada wanita usia subur dalam melakukan pemeriksaan payudara sendiri memiliki kategori baik karena adanya informasi dan stimulus yang didapatkan wanita usia subur dari pemberian video animasi. Pemeberian video animasi memberikan pengetahuan untuk meningkatkan pengetahuan wanita usia subur dalam melakukan pemeriksaan payudara sendiri. Penelitian yang dilakukan oleh Sulastri (2012) di SMAN 9 Balik Papan menyatakan bahwa penyuluhan kesehatan pemeriksaan SADARI dengan media video dapat meningkatkan pengetahuan remaja putri. Penellitian suastina dkk., (2013) menjelaskan bahwa penyuluhan kesehatan sangat berperan penting untuk meningkatkan pengetahuan dan perilaku wanita untuk melakukan SADARI. Penelitian Abdullah, Tangka, \& Rottie (2013), menjelaskan bahwa pengetahuan wanita tentang resiko dan manfaat dari deteksi dini kanker payudara berpengaruh positif terhadap keyakinan mereka tentang kesehatan,sikap dan perilaku, sehingga perawatan kesehatan profesional dapat mengembangkan program kesehatan payudara yang efektif.

Tabel 2

Hasil Tabulasi Silang dengan Marginal Homogeneity Test

\begin{tabular}{|c|c|c|c|c|c|}
\hline \multicolumn{6}{|c|}{ Sesudah Diberikan Perlakuan } \\
\hline \multirow{3}{*}{ Sebelum diberikan perlakuan } & & Cukup (\%) & Baik (\%) & Total (\%) & Pvalue \\
\hline & Kurang & $12(25 \%)$ & $12(25 \%)$ & $24(50 \%)$ & \multirow{3}{*}{0,000} \\
\hline & Cukup & $2(4,2 \%)$ & $22(45,8 \%)$ & $24(50 \%)$ & \\
\hline Total & & $14(29,2 \%)$ & $34(70,8 \%)$ & $48(100 \%)$ & \\
\hline
\end{tabular}

Sumber: Data Primer Diolah, 2021 
Responden yang memiliki pengetahuan baik menyebabkan mampu melakukan pemeriksaan payudara sendiri secara mandiri dengan baik dan benar tanpa harus menunggu edukasi dari tenaga kesehatan. Responden yang memiliki pengetahuan baik seperti pengertian SADARI, tujuan,waktu pelaksanaan, cara melakukan dan masalah yang ditemukan saat melakukan pemeriksaan payudara sendiri. Hal ini membuktikan bahwa pemberian video animasi tentang pengetahuan SADARI efektif mampu meningkatkan pengetahuan wanita usia subur tentang pemeriksaan payudara sendiri. Pengaruh penyuluhan kesehatan dengan media video animasi tentang Pengetahuan SADARI Pada Wanita Usia Subur Di RW 06 RT 07 Kelurahan Tlogomas kecamatan lowokwaru Kota Malang.

Berdasarkan hasil penelitian pada wanita usia subur ada pengaruh media video animasi terhadap pengetahuan SADARI wanita usia subur dalam melakukan pemeriksaan payudara sendiri di Rw 06 Rt 07 Kelurahan Tlogomas Kecamatan Lowokwaru Kota Malang. Hal ini membuktikan bahwa terdapat peningkatan pengetahuan SADARI pada responden menjadi baik sesudah diberikan video animasi tentang pengetahuan SADARI.

Hasil penelitian membuktikan bahwa pemberian video animasi efektif mampu meningkatkan pengetahuan wanita usia subur dalam melakukan pemeriksaan payudara sendiri. upaya yang dilakukan untuk mencengah kanker payudara dengan melaksanakan gaya hidup sehat dan melakukan SADARI (Nisman, 2015). Pemberian video animasi bertujuan untuk memberikan informasi untuk meningkatkan pengetahuan pada wanita usia subur dalam penanganan pencegahan kanker payudara secara dini. Penelitian ini sesuai dengan yang dilakukan oleh Devi \& Warsitipada (2013), menunjukkan bahwa ada media audio visual yang mempengaruhi perpanjangan video ke tingkat konwlegde sadar. Hasil penelitian ini sesuai dengan penelitian yang dilakukan oleh Pieters (2011), menunjukkan bahwa hal ini sering dikaitkan dengan keputusan dari seorang remaja dalam melakukan ilmu pengetahuan yang dimilikinya dalam melakukan SADARI. Pembelajaran edukasi pengetahuan SADARI pada wanita usia subur agar dapat diterapkan untuk pemeriksaan payudara sendiri di rumah, sehingga wanita usia subur wajib memiliki pengetahuan yang baik tentang SADARI dalam penanganan terjadinya kanker payudara secara dini. Manfaat video animasi tentang SADARI yaitu meningkatkan pengetahuan, ketrampilan dan kempapuan menangani terjadinya kanker payudara secara dini secara benar.

Ada 2 responden yang sebenarnya dalam perlakukan memiliki peningkatan hanya saja masih ada di rentang yang sama yaitu di kategori cukup. Ada faktor lain yang mempengaruhi pengetahuannya yaitu pendidikan, sebenarnya 2 responden tersebut nilainya meningkat hanya saja tetap di kategori yang sama. Pendidikan berarti bimbingan yang diberikan oleh seseorang terhadap perkembangan orang lain menuju ke arah suatu cita-cita tertentu. Makin tinggi tingkat pendidikan seseorang maka makin mudah dalam menerima informasi, sehingga semakin banyak pula pengetahuan yang dimiliki. informasi, Informasi yang diperoleh baik melalui pendidikan formal maupun non formal dapat memberikan pengaruh jangka pendek (immediate impact) sehingga menghasilkan perubahan atau peningkatan pengetahuan.

\section{SIMPULAN}

Sebelum diberikan edukasi dengan media video animasi tentang pengetahuan SADARI, wanita usia subur memiliki pengetahuan dalam kategori kurang dan cukup masingmasing dalam persentase yang sama. Sesudah diberikan edukasi di dapatkan sebagaian besar pengetahuan dalam kategori baik. Ada pengaruh edukasi dengan media video animasi tentang pengetahuan SADARI pada wanita usia subur di Kelurahan Tlogomas Kecamatan Lowokwaru Kota Malang.

\section{DAFTAR PUSTAKA}

Abdullah N., Tangka J., \& Rottie J. . (2013). Hubungan Pengetahuan Tentang Kanker Payudara Dengan Cara Periksa Payudara Sendiri Pada Mahasiswi Semester IV Program Studi Ilmu Keperawatan Fakultas Kedokteran Universitas Sam Ratulangi. ejournal keperawatan (eKp) 1 (1). Universitas Sam Ratulangi Manado. 
Bustan, M. N. (2007). Epidemiologi : penyakit tidak menular. Cetakan 2. Jakarta : Rineka Cipta.

Dinas Kesehatan Malang. (2019). Profil Kesehatan Kota Malang Tahun 2018. Malang: Pemerintah Kota Malang.

Dinkes Jatim. (2019). Jumlah Penderita Kanker Payudara di Jatim Terus Meningkat. Ini yang Dilakukan Dinas Kesehatan Jatim. Surabaya: Surya.

Ervina, D.S.,\& Warsiti. (2013). Pengaruh penyuluhan media audio visual video terhadap tingkat pengetahuan pemeriksaan payudara sendiri (SADARI) pada kader posyandu di tejokusuman Rw 04 notoprajan yogyakarta tahun 2013 . STIKES Aisyiyah Yogyakarta

Globocan. (2018). Kanker hari ini. Badan Internasional untuk Penelitian tentang Kanker. http://gco.iarc.fr/ - Diakses Oktober 2018

Hendra. (2017). Pengaruh Penyuluhan terhadapPeningkatanPengetahuan Ibu tentang Konsumsi Sayur dan Buah. Aceh: Poltekkes Kemenkes Aceh

Ibrahim. (2015). Pengaruh Penyuluhan Kesehatan SADARI terhadap tingkat pengetahuan dan skill kader kesehatan di Desa Purwajaya dan Desa SidarahayuCiamis. In Prosiding Seminar Nasional Keperawatan Maternitas Tahun 2015. Bandung: Ikatan Perawat Maternitas Indonesia Provinsi Jawa Barat pp. 132137.

Kemenkes RI. (2019). Hari Kanker Sedunia 2019. Jakarta: Biro Komunikasi dan Pelayanan Masyarakat, Kementerian Kesehatan RI.

Nisman, W. (2015). Lima Menit Kenali Payudara.Yogyakarta: C.V Andi

Notoatmodjo. (2014). Konsep Ilmu Keperawatan. Jakarta : Salemba Medika.

Notoatmodjo. (2017). Metodelogi Penelitian Kesehatan, PT Rineka Cipta, Jakarta
Patandianan R. E., Suarayasa K., \& Towidjojo V. D. (2015). Hubungan Antara Tingkat Pengetahuan Dan Sikap Dengan Tindakan Tentang Pemeriksaan Payudara Sendiri (Sadari) Pada Wanita Usia Subur (Wus) Di Kelurahan Nunu Kecamatan Tatanga. MEDIKA TADULAKO, Jurnal Ilmiah Kedokteran 2 (2). Universitas Tadulako.

Pieters, Herry, Jariwarti, Bethsaida \& Martih, SD. (2011). Pengantar Psikopatologi Untuk Keperawatan. Jakarta. C.V Andi

Suastina, I. D. A. R., Ticoalu H., \& Onibala F. (2013). Pengaruh Pendidikan Kesehatan Terhadap Tingkat Pengetahuan Siswi Tentang Sadari Sebagai Deteksi Dini Kanker Payudara Di Sma Negeri 1 Manado. ejurnal Keperawatan 1 (1). Universitas Sam Ratulangi Manado.

Suraya H. N., Romus i., \& Suyanto. (2015). Pengaruh Penyuluhan Terhadap Pengetahuan Dan Sikap Ibu Pkk Tentang Pemeriksaan Payudara Sendiri (SADARI). Jurnal Online Mahasiswa 2 (2). Universitas Riau.

Sulastri., Ridwan M. Thaha., Syamsiar Russeng. (2012). Pengaruh Penyuluhan Kesehatan Menggunakan Video Dalam Pemeriksaan Payudara Sendiri (SADARI) Terhadap Perubahan Pengetahuan dan Sikap Remaja Putri di SMA 09 Balikpapan Tahun 2012. Jurnal Promosi Kesehatan Nusantara Indonesia. Juli-Desember 2012. Halaman 1-10

WHO. (2019). Eastern Mediterranean Health Journal. http://www.emro.who.int/ emhj-volume-17/issue-6/article8.html. Diakses pada tanggal 18 Desember 2020. 